\title{
Polymorphic Amplified Typing Sequences and Pulsed-Field Gel Electrophoresis Yield Comparable Results in the Strain Typing of a Diverse Set of Bovine Escherichia coli 0157:H7 Isolates
}

\author{
Indira T. Kudva, ${ }^{1}$ Margaret A. Davis, ${ }^{2,3}$ Robert W. Griffin, ${ }^{4}$ Jeonifer Garren, ${ }^{4}$ \\ Megan Murray, ${ }^{4,5}$ Manohar John, ${ }^{4,6,7}$ Carolyn J. Hovde, ${ }^{8}$ and Stephen B. Calderwood ${ }^{4,6,9}$ \\ ${ }^{1}$ Food Safety and Enteric Pathogens Research Unit, National Animal Disease Center, Agricultural Research Service, \\ U.S. Department of Agriculture, Ames, IA 50010, USA \\ ${ }^{2}$ Department of Microbiology, Molecular Biology and Biochemistry, University of Idaho, Moscow, ID 83843, USA \\ ${ }^{3}$ Department of Veterinary Microbiology and Pathology, College of Veterinary Medicine, Washington State University, Pullman, \\ WA 99164, USA \\ ${ }^{4}$ Division of Infectious Diseases, Massachusetts General Hospital, Boston, MA 02114, USA \\ ${ }^{5}$ Department of Epidemiology, Harvard School of Public Health, Boston, MA 02115, USA \\ ${ }^{6}$ Department of Medicine, Harvard Medical School, Boston, MA 02115, USA \\ ${ }^{7}$ Pathovacs Inc., Ames, IA 50010, USA \\ ${ }^{8}$ School of Food Sciences, University of Idaho, Moscow, ID 83843, USA \\ ${ }^{9}$ Department of Microbiology and Immunobiology, Harvard Medical School, Boston, MA 02115, USA
}

Correspondence should be addressed to Indira T. Kudva, ikudva2002@yahoo.com

and Stephen B. Calderwood, scalderwood@partners.org

Received 25 June 2012; Accepted 25 July 2012

Academic Editor: Giuseppe Comi

Copyright ( $) 2012$ Indira T. Kudva et al. This is an open access article distributed under the Creative Commons Attribution License, which permits unrestricted use, distribution, and reproduction in any medium, provided the original work is properly cited.

\begin{abstract}
Polymorphic amplified typing sequences (PATS), a PCR-based Escherichia coli O157:H7 (O157) strain typing system, targets insertions-deletions and single nucleotide polymorphisms at XbaI and AvrII restriction enzyme sites, respectively, and the virulence genes (stxl, stx2, eae, hlyA) in the O157 genome. In this study, the ability of PATS to discriminate O157 isolates associated with cattle was evaluated. An in-depth comparison of 25 bovine O157 isolates, from different geographic locations across Northwest United States, showed that about $85 \%$ of these isolates shared the same dendogram clade by PATS and pulsed-field gel electrophoresis (PFGE), irrespective of the restriction enzyme sites targeted. The Pearson's correlation coefficient, $r$, calculated at about $0.4,0.3$, and 0.4 for XbaI-based, AvrII-based and combined-enzymes PATS and PFGE similarities, respectively, indicating that these profiles shared a good but not high correlation, an expected inference given that the two techniques discriminate differently. Isolates that grouped differently were better matched to their locations using PATS. Overall, PATS discriminated the bovine $\mathrm{O} 157$ isolates without interpretive biases or sophisticated analytical software, and effectively complemented while not duplicating PFGE. With its quick turnaround time, PATS has excellent potential as a convenient tool for early epidemiological or food safety investigations, enabling rapid notification/implementation of quarantine measures.
\end{abstract}

\section{Introduction}

Escherichia coli O157:H7 (O157) causes an estimated 63,153 domestically acquired foodborne illnesses, 2,138 hospitalizations and 20 deaths annually in the United States [17]. Although a $44 \%$ decline in O157 cases was reported for the year 2010, over the past six years at least 13 different multistate O157 outbreaks have occurred, many of which have had a direct link to beef or produce possibly contaminated with manure $[6,7]$. In fact, with cattle being the primary reservoir for this human pathogen [2-4], most human infections occur through food sources that are 
TABLE 1: Summary of bovine E. coli O157:H7 isolates used in this study.

\begin{tabular}{|c|c|c|c|}
\hline Isolates & Source & Location & Collection dates \\
\hline 5 & Dairy cattle & Yakima Valley, Washington & $7 / 22 / 1991$ \\
\hline 168 & Dairy cattle & Northwest Idaho & 6/7/1993 \\
\hline 214 & Dairy cattle & Northwest Washington & $6 / 30 / 1993$ \\
\hline 268 & Dairy cattle & West Oregon & 8/3/1993 \\
\hline 425 & Dairy cattle & Northwest Washington & $10 / 26 / 1993$ \\
\hline 528 & Dairy calf & Central Washington & $4 / 21 / 1994$ \\
\hline 757 & Dairy cattle & Northwest Washington & $6 / 21 / 1994$ \\
\hline 806 & Dairy cattle & South Idaho & $7 / 5 / 1994$ \\
\hline 817 & Dairy cattle & West Oregon & $7 / 6 / 1994$ \\
\hline 807 & Dairy cattle & Central Idaho & $7 / 6 / 1994$ \\
\hline 827 & Dairy cattle & West Oregon & $7 / 11 / 1994$ \\
\hline 908 & Dairy cattle & South Idaho & $7 / 12 / 1994$ \\
\hline 928 & Dairy cattle & Northwest Oregon & $7 / 13 / 1994$ \\
\hline 935 & Dairy cattle & Northwest Oregon & $7 / 13 / 1994$ \\
\hline 961 & Dairy cattle & Northwest Oregon & $7 / 18 / 1994$ \\
\hline 977 & Dairy cattle & Central Idaho & $7 / 25 / 1994$ \\
\hline 1015 & Dairy cattle & Northwest Oregon & $7 / 25 / 1994$ \\
\hline 1016 & Dairy cattle & South Central Washington & $7 / 27 / 1994$ \\
\hline 1041 & Dairy cattle & Northwest Oregon & $8 / 1 / 1994$ \\
\hline 1273 & Dairy cattle & Southwest Oregon & $8 / 30 / 1994$ \\
\hline 1286 & Dairy cattle & Western Washington & $9 / 2 / 1994$ \\
\hline 1328 & Dairy cattle & Washington Basin & 9/13/1994 \\
\hline 1492 & Feedlot & Unknown & $10 / 3 / 1994$ \\
\hline 5671 & Mill feed & WSU ${ }^{a}$ Feedmill & $1 / 5 / 1999$ \\
\hline 5974 & Dairy cattle & WSU Dairy & 9/1/1999 \\
\hline
\end{tabular}

'WSU: Washington State University, Pullman, WA.

cattle derived (undercooked hamburger) or contaminated by cattle feces, such as salad vegetables, water, apple cider, and unpasteurized milk. With the current mechanization and globalization trends in food production and distribution, the need to monitor produce for foodborne pathogens such as $\mathrm{O} 157$ continues to remain critical to the prevention of extensive outbreaks, as is rapid epidemiological surveillance to identify and eliminate potential sources from the food chain.

Pulsed-field gel electrophoresis (PFGE) is the bacterial strain typing method of choice, regularly used by diagnostic and epidemiological laboratories to type O157 strains. To overcome the drawbacks of standard PFGE methodology, several modifications have been implemented that seek to address issues of, restriction enzyme inhibition, DNA degradation, variations in electrophoretic patterns between gels, improper resolution of digested DNA, subjective interpretation of these patterns even with sophisticated patternrecognition computer software, and most importantly to decrease the turnaround time from 3 to 4 days to within $24 \mathrm{~h}$, so data can be made available in a timely manner [8-12]. Even with all the modifications, it has been noted that single-restriction enzyme PFGE gives a poor measure of genetic relatedness as it does not resolve the entire repertoire of DNA fragments generated following restriction digestion [13].
Consequently, this has led to the incorporation of other genome-sequence-based techniques, such as multilocus sequence typing (MLST) and/or multilocus variable-number tandem repeat analysis (MLVA), either in conjunction with PFGE or by themselves, to type $\mathrm{O} 157$ isolates. However, even these methodologies cannot speed up the process as they rely primarily on generation of sequencing quality DNA, analysis of multiple genes or distances between tandem repeat sequences, which require complex instrumentation, and interpreting software $[14,15]$. Hence, all these techniques would be useful in detailed, comprehensive analysis for followup cross-referencing, and banking purposes, rather than being the "first response" tools to rapidly sort out linked and unlinked cases/sources in an outbreak situation.

In previous studies, a touchdown PCR-based O157 strain typing system that incorporated polymorphisms at the XbaIand AvrII-restriction sites, and amplified four virulence genes in the $\mathrm{O} 157$ genome was standardized against $46 \mathrm{O} 157$ isolates from different sources and outbreaks [16-18]. This system termed the polymorphic amplified typing sequences (PATS) was not only able to provide a DNA fingerprint but also provide virulence profiles of the examined O157 isolates. PATS was less discriminatory when only one of the restriction enzyme sites was targeted but in the combination indicated above, PATS matched related isolates better than PFGE while differentiating between the unrelated isolates [16-18]. 
TABle 2: XbaI -based PATS profiles of the 25 bovine O157 isolates. AvrII-based PATS profiles of the 25 bovine O157 isolates.

(a)

\begin{tabular}{|c|c|c|c|c|c|c|c|c|c|}
\hline \multirow[t]{2}{*}{ PATS type $^{a}$} & \multicolumn{8}{|c|}{$\begin{array}{l}\text { PCR amplification and restriction digestion patterns of amplicons obtained } \\
\text { using } 8 \text { PATS primer pairs }{ }^{\mathrm{b}}\end{array}$} & \multirow[t]{2}{*}{ Isolates $^{\mathrm{c}}$} \\
\hline & IK8 & IK19 & IK25 & IK114 & IK118 & IK123 & IKB3 & IKB5 & \\
\hline 1 & 2 & 2 & 0 & 2 & 2 & 2 & 2 & 2 & $168,908,928$ \\
\hline 2 & 0 & 2 & 0 & 2 & 2 & 2 & 2 & 2 & 977 \\
\hline 3 & 2 & 2 & 0 & 2 & 2 & 2 & 0 & 2 & $5,757,806,817,1015,1492$ \\
\hline 4 & 0 & 2 & 0 & 2 & 2 & 2 & 0 & 2 & 807 \\
\hline 5 & 2 & 2 & 0 & 2 & 2 & 2 & 0 & 0 & $268,827,935$ \\
\hline 6 & 2 & 2 & 0 & 2 & 2 & 0 & 0 & 0 & $1041,5671,5974$ \\
\hline 7 & 2 & 2 & 0 & 0 & 2 & 2 & 2 & 0 & 1273 \\
\hline 8 & 2 & 2 & 0 & 0 & 2 & 2 & 0 & 0 & $214,528,1016,1286,1328$ \\
\hline 9 & 2 & 2 & 0 & 2 & 0 & 2 & 0 & 0 & 425 \\
\hline 10 & 0 & 2 & 0 & 0 & 2 & 0 & 0 & 0 & 961 \\
\hline
\end{tabular}

(b)

\begin{tabular}{|c|c|c|c|c|c|c|c|c|}
\hline \multirow[t]{2}{*}{ PATS type ${ }^{a}$} & \multicolumn{7}{|c|}{$\begin{array}{l}\text { PCR amplification and restriction digestion patterns of amplicons obtained } \\
\text { using } 7 \text { PATS primer pairs }{ }^{\mathrm{d}}\end{array}$} & \multirow[t]{2}{*}{ Isolates $^{\mathrm{c}}$} \\
\hline & IKNR3 & IKNR7 & IKNR10 & IKNR12 & IKNR16 & IKNR27 & IKNR33 & \\
\hline 1 & 2 & 2 & 2 & 2 & 2 & 2 & 2 & $5,168,817,908,928,977,1015,1492$ \\
\hline 2 & 2 & 2 & 2 & 0 & 2 & 2 & 2 & $268,757,806,807$ \\
\hline 3 & 2 & 2 & 2 & 2 & 1 & 2 & 2 & 1041 \\
\hline 4 & 0 & 2 & 2 & 2 & 1 & 2 & 2 & $827,5671,5974$ \\
\hline 5 & 1 & 2 & 2 & 2 & 1 & 2 & 0 & $214,528,961,1016,1273,1286,1328$ \\
\hline 6 & 2 & 1 & 1 & 2 & 1 & 2 & 2 & 425,935 \\
\hline
\end{tabular}

${ }^{a}$ PATS types are designated arbitrarily with different numbers.

${ }^{b}$ Prefixes of each PATS primer pair A/B are indicated. 0: no amplicon; 2: amplicon with one XbaI site.

${ }^{\mathrm{C} B o v i n e}$ E. coli O157:H7 isolates from different locations that fell within a given PATS type.

${ }^{\mathrm{d}}$ Prefixes of each PATS primer pair A/B are indicated. 0: no amplicon; 1: amplicon without AvrII site; 2: amplicon with one AvrII site.

In this study, we decided to evaluate PATS against a diverse set of bovine $\mathrm{O} 157$ isolates and compare the profiles generated, with the PFGE patterns for the same, at length. For this, we targeted the same combinations of restriction enzyme sites. Although PATS directly sorts the polymorphisms at the restriction enzyme sites, and PFGE analyzes the DNA fragments generated as a result of these polymorphisms, we wanted to identify the degree of similarity between the two techniques and also ascertain if PATS would continue to maintain its ability to relate/discriminate bovine isolates as it did for human isolates in earlier studies [18].

\section{Materials and Methods}

2.1. Bacteria. Twenty-five $\mathrm{O} 157$ bovine isolates from various farms along the northwest region of United States (Idaho, Washington, and Oregon states) were obtained from collections maintained at the Field Disease Investigation Unit, College of Veterinary Medicine, Washington State University, Pullman, WA. The identification code used for each of these isolates is as indicated in Table 1.
2.2. PATS. PCR was done using conditions and primers as described previously [16-18]. Briefly, colony lysate of each O157 strain was tested against individual primer pairs, using the hot start PCR technique [19] in combination with a touchdown PCR profile [20]. To create this profile, an amplification segment of 20 cycles was set where the annealing temperature started at $73^{\circ} \mathrm{C}$ to touchdown at $53^{\circ} \mathrm{C}$ at the end of those cycles. Then, another amplification segment of 10 cycles was set, using the last annealing temperature of $53^{\circ} \mathrm{C}$. Each reaction was done in triplicate to confirm profiles generated. Primer pairs targeting the 8 polymorphic XbaIand 7 polymorphic AvrII-restriction enzyme sites, and the four virulence genes encoding the Shiga toxin $1\left(s t x_{1}\right)$, shiga toxin $2\left(\right.$ st $\left.x_{2}\right)$, Intimin- $\gamma$ (eae), and hemolysin-A (hlyA), were used [16-18]. PCR reactions were purified using the QIAquick PCR purification kit (Qiagen, Valencia, Ca.), and all reactions, except for those amplifying virulence genes, were digested with the appropriate restriction enzyme (New England Biolabs, Beverly, Ma.) to confirm the presence of the restriction site within amplicons prior to resolution on a $4 \%$ agarose gel.

Presence or absence of amplicons was recorded as before $[17,18]$. Briefly, for the virulence genes, the presence of an 
TABLE 3: Combined-PATS profiles for the 25 bovine O157 isolates.

\begin{tabular}{|c|c|c|c|c|c|c|c|c|c|c|c|c|c|c|c|c|c|c|c|c|c|}
\hline \multirow{3}{*}{ PATS type ${ }^{a}$} & \multicolumn{20}{|c|}{$\begin{array}{l}\text { PCR amplification and restriction digesti } \\
15 \text { PATS }-4 \text { virulence gene primer pairs }\end{array}$} & \multirow{3}{*}{ Isolates $^{c}$} \\
\hline & \multicolumn{9}{|c|}{ Polymorphic $X b a \mathrm{I}$ sites } & \multicolumn{7}{|c|}{ Polymorphic AvrII sites } & \multicolumn{4}{|c|}{ Virulence genes } & \\
\hline & $\begin{array}{l}\infty \\
\ddot{v}\end{array}$ & $\stackrel{\vartheta}{\vec{\Xi}}$ & $\stackrel{\mathscr{\imath}}{\mathscr{\imath}}$ & $\stackrel{Ð}{\Xi}$ & $\stackrel{\infty}{\exists}$ & $\underset{\Xi}{ٍ}$ & $\ddot{\theta}$ & $\stackrel{n}{\theta}$ & - & $\begin{array}{l}\mathscr{Z} \\
\underline{Z}\end{array}$ & 艺 & $\begin{array}{l}^{1} \\
\text { 兄 } \\
\text { 光 }\end{array}$ & 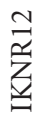 & 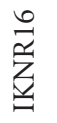 & 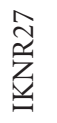 & $\underset{\mathscr{n}}{\tilde{Z}}-$ & $\overrightarrow{5}$ & $\underset{w}{\breve{w}}$ & 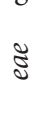 & $\stackrel{\frac{\pi}{2}}{\Sigma}$ & \\
\hline $1{\text { (previous } 19)^{\mathrm{d}}}^{\mathrm{d}}$ & 2 & 2 & 0 & 2 & 2 & 2 & 2 & 2 & & 2 & 2 & 2 & 2 & 2 & 2 & 2 & 1 & 1 & 1 & 1 & $168,908,928$ \\
\hline 2 (previous 2) & 0 & 2 & 0 & 2 & 2 & 2 & 2 & 2 & & 2 & 2 & 2 & 2 & 2 & 2 & 2 & 1 & 1 & 1 & 1 & 977 \\
\hline 3 (previous 18) & 2 & 2 & 0 & 2 & 2 & 2 & 0 & 2 & & 2 & 2 & 2 & 2 & 2 & 2 & 2 & 1 & 1 & 1 & 1 & $5,817,1015,1492$ \\
\hline 4 (previous 16) & 2 & 2 & 0 & 2 & 2 & 2 & 0 & 2 & & 2 & 2 & 2 & 0 & 2 & 2 & 2 & 1 & 1 & 1 & 1 & 757,806 \\
\hline 5 & 0 & 2 & 0 & 2 & 2 & 2 & 0 & 2 & & 2 & 2 & 2 & 0 & 2 & 2 & 2 & 1 & 1 & 1 & 1 & 807 \\
\hline 6 & 2 & 2 & 0 & 2 & 2 & 2 & 0 & 0 & & 2 & 2 & 2 & 0 & 2 & 2 & 2 & 1 & 1 & 1 & 1 & 268 \\
\hline 7 & 2 & 2 & 0 & 2 & 2 & 0 & 0 & 0 & & 2 & 2 & 2 & 2 & 1 & 2 & 2 & 1 & 1 & 1 & 1 & 1041 \\
\hline 8 & 2 & 2 & 0 & 2 & 2 & 0 & 0 & 0 & & 0 & 2 & 2 & 2 & 1 & 2 & 2 & 1 & 1 & 1 & 1 & 5671,5974 \\
\hline 9 & 2 & 2 & 0 & 0 & 2 & 2 & 2 & 0 & & 1 & 2 & 2 & 2 & 1 & 2 & 0 & 1 & 0 & 1 & 1 & 1273 \\
\hline 10 & 2 & 2 & 0 & 2 & 2 & 2 & 0 & 0 & & 0 & 2 & 2 & 2 & 1 & 2 & 2 & 0 & 1 & 1 & 1 & 827 \\
\hline 11 (previous 8) & 2 & 2 & 0 & 2 & 2 & 2 & 0 & 0 & & 2 & 1 & 1 & 2 & 1 & 2 & 2 & 0 & 1 & 1 & 1 & 935 \\
\hline 12 & 2 & 2 & 0 & 0 & 2 & 2 & 0 & 0 & & 1 & 2 & 2 & 2 & 1 & 2 & 0 & 0 & 1 & 1 & 1 & $214,528,1016,1328$ \\
\hline 13 & 2 & 2 & 0 & 2 & 0 & 2 & 0 & 0 & & 2 & 1 & 1 & 2 & 1 & 2 & 2 & 0 & 1 & 1 & 1 & 425 \\
\hline 14 & 2 & 2 & 0 & 0 & 2 & 2 & 0 & 0 & & 1 & 2 & 2 & 2 & 1 & 2 & 0 & 0 & 1 & 1 & 0 & 1286 \\
\hline 15 & 0 & 2 & 0 & 0 & 2 & 0 & 0 & 0 & & 1 & 2 & 2 & 2 & 1 & 2 & 0 & 0 & 1 & 1 & 1 & 961 \\
\hline
\end{tabular}

${ }^{a}$ PATS types are designated arbitrarily with different numbers.

${ }^{b}$ Prefixes of each PATS primer pair A/B and virulence gene primer pair F/R are indicated. 0: no amplicon; 1: amplicon without AvrII site; 2: amplicon with one XbaI or AvrII site.

${ }^{\mathrm{c} B o v i n e}$ E. coli O157:H7 isolates from different locations that fell within a given PATS type.

${ }^{\mathrm{d}}$ Identical profiles observed in previous study [18].

amplicon was recorded as "1" (as these lacked either of the restriction enzyme sites being tested) and " 0 " for the absence of an amplicon. For PCR targeting the polymorphic XbaI restriction sites, presence of an amplicon was recorded as a "2" (as all amplicons could be digested into 2 fragments following enzymatic cleavage by the $X b a I$ restriction enzyme) and as " 0 " in the absence of an amplicon. Likewise, for PCR targeting the AvrII restriction site, presence of an amplicon was recorded as "1" if the amplicon had no AvrII site, "2" if the amplicon had an AvrII site that resulted in it being digested into 2 fragments following enzymatic cleavage by the AvrII restriction enzyme and " 0 " in the absence of an amplicon [18].

2.3. PFGE. Standard PFGE methods were used to analyze the 25 bovine isolates as previously described [13, 18]. Briefly, the genomic DNA of each isolate was embedded in separate agarose plugs and digested at $37^{\circ} \mathrm{C}$ for $2 \mathrm{~h}$ with $30 \mathrm{U}$ of $X b a \mathrm{I}$ or $B \ln \mathrm{I}(A v r \mathrm{II})$ (Gibco BRL, Grand Island, N.Y.) per plug. The plugs were loaded onto a $1 \%$ agarose-tris buffer gel (SeaKem Gold Agarose; BioWhittaker Molecular Applications, Rockland, Maine), and PFGE was performed with a CHEF Mapper XA apparatus (Bio-Rad Laboratories, Hercules, Calif.). DNA was electrophoresed for $18 \mathrm{~h}$ at a constant voltage of $200 \mathrm{~V}(6 \mathrm{~V} / \mathrm{cm})$, with a pulse time of 2.2 to $54.2 \mathrm{~s}$, an electric field angle of $120^{\circ}$, and a temperature of $14^{\circ} \mathrm{C}$, before being stained with ethidium bromide. Gel images were analyzed using Bionumerics (Applied Maths, Saint-Martens-Latem, Belgium).

2.4. Data Analysis. (i) PATS dendograms: dendograms were constructed by coding molecular data as described previously [16-18]. Briefly, the presence or absence of each of the 15 amplicons (representing 8 polymorphic $X b a \mathrm{I}$ and 7 polymorphic AvrII sites) was coded as a dichotomous variable. Characters representing gain or loss of a restriction site recognized by AvrII were weighted to reflect the increased probability of losing a site than gaining one; however, such weighting had no impact on the resulting dendogram. Trees were constructed using the unweighted pair-group method with arithmetic means (UPGMA) option in the phylogenetic analysis using parsimony (PAUP; Sinauer Associates, Inc., Publishers, Sunderland, Ma.). (ii) PFGE dendograms: Dendograms were constructed using UPGMA cluster analysis based on Dice coefficients performed in Bionumerics, for XbaI- and AvrII-based PFGE patterns [21]. Combined Dice coefficients were then used to generate the $\mathrm{XbaI}$ and AvrII-combined-PFGE dendogram. (iii) Similarities: Bionumerics was used to determine Dice similarity coefficients for PFGE banding patterns as described previously, using the formula, $2 n / a+b$, where $n=$ number of matching bands and $\mathrm{a}+\mathrm{b}=$ total number of bands 


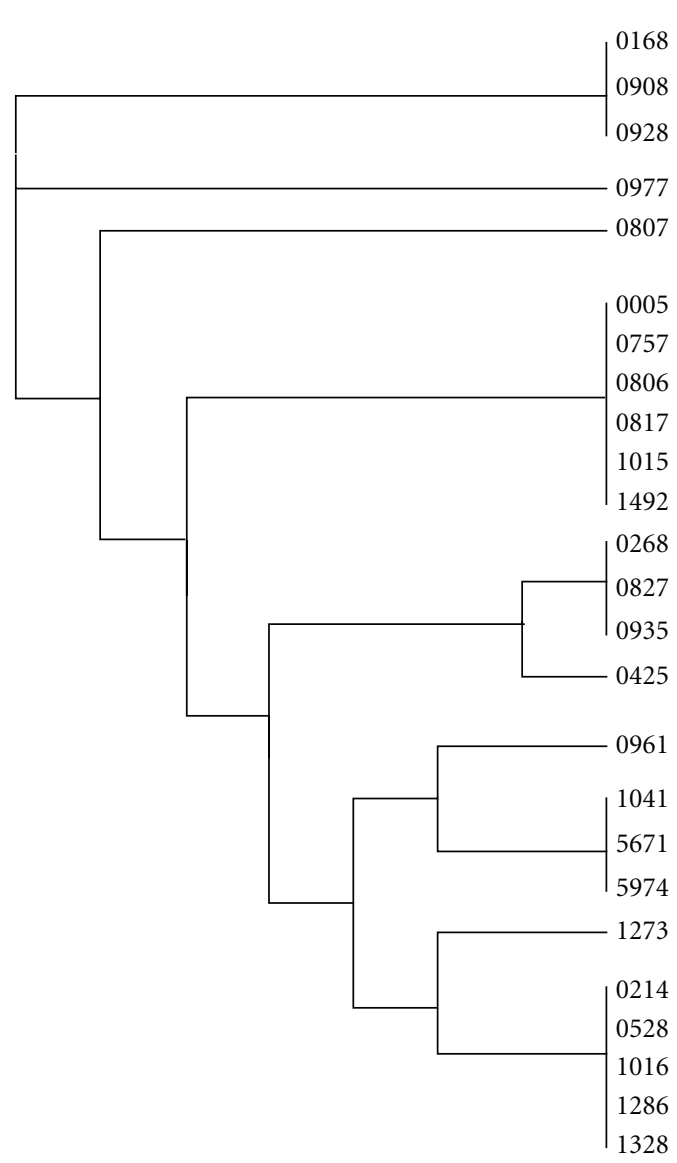

(a) XbaI-based PATS
Dice (Opt: 1\%) (Tol 1\%-1\%) $(H>0 \% S>0 \%)[0 \%-0.7 \%][8.5 \%-89.8 \%]$
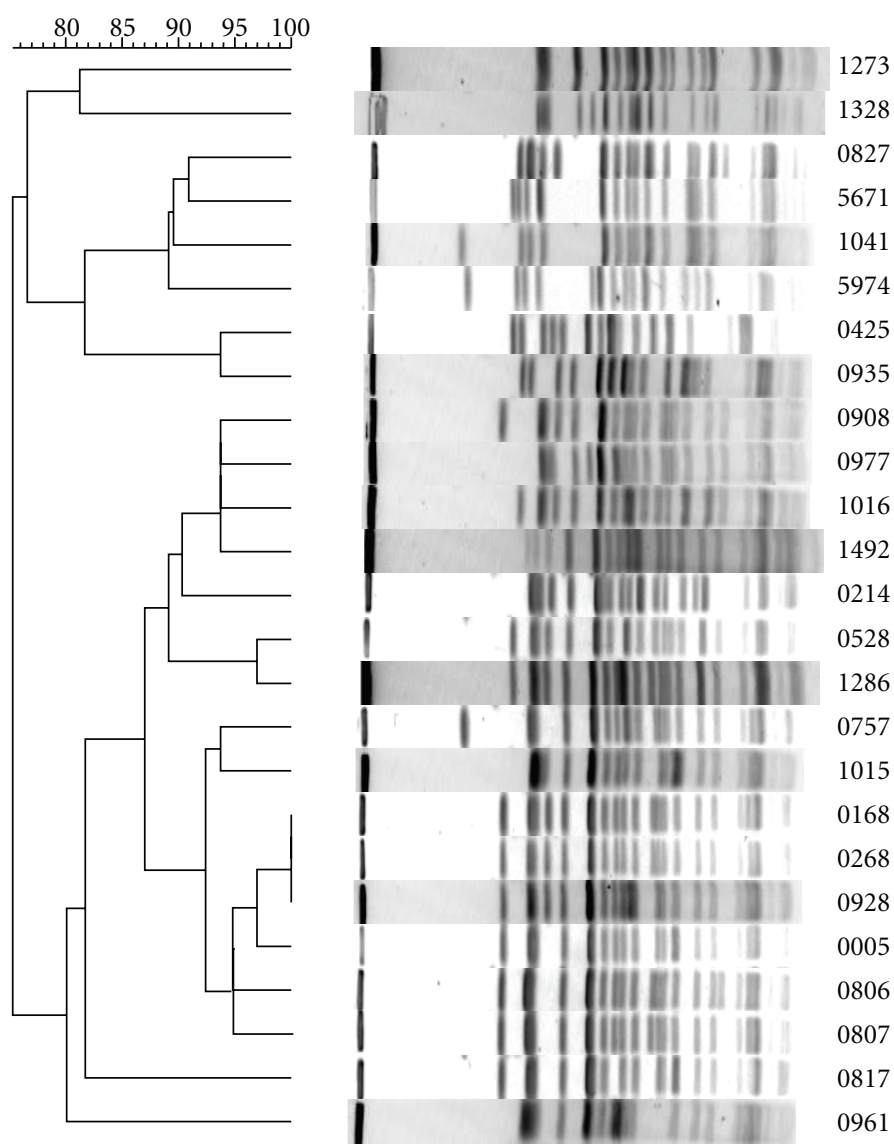

(b) XbaI-based PFGE

FIGURE 1: Analysis of relatedness between 25 bovine O157 isolates. (a) Dendogram for XbaI-based PATS profiles was constructed using the UPGMA option in the phylogenetic analysis using parsimony (PAUP; Sinauer Associates, Inc., Publishers, Sunderland, Ma.). (b) Dendogram for XbaI-based PFGE profiles was constructed using the UPGMA cluster analysis based on Dice coefficients performed in Bionumerics (Applied Maths, Saint-Martens-Laatem, Belgium). Percent tolerance used is shown above the dendogram.

(matching and nonmatching) being compared between a pair of O157 isolates [13, 21]. For PATS, this coefficient was manually derived for each isolate pair using the modified formula, $\{2 \times$ the number of concordant markers $\} \div$ \{total number of markers being compared\}. The total number of markers being compared between a pair of $\mathrm{O} 157$ isolates was 12 for XbaI-based PATS, and 11 for AvrII-based PATS, including the virulence genes. The Dice similarity coefficients for PFGE and PATS were then used to calculate Pearson's correlation coefficients as shown in the scatter plots.

\section{Results}

3.1. PATS Screening of the 25 Bovine O157 Isolates. All O157 isolates were analyzed for polymorphic XbaI- and AvrIIrestriction sites, along with virulence genes. Independent of each other, XbaI-based PATS generated 10 different profiles, while AvrII-based PATS generated 6 different profiles (Tables 2(a) and 2(b)). However, in combination along with the four virulence genes, PATS analysis resulted in 15 distinct profiles demonstrating an increase in discrimination as observed previously (Table 3) [18]. These distinct profiles were clustered into smaller, related clades in the dendograms generated in PAUP. As shown in Figures 1(a), 2(a), and 3(a), the XbaI-based, AvrII-based, and combined PATS generated 5, 3, and 7 clades, respectively. Interestingly, five PATS profiles, 1, 2, 3, 4, and 11 (Table 3), were identical to the PATS profiles $19,2,18,16$, and 8 , respectively, observed in a previous analysis of 46 unrelated $\mathrm{O} 157$ isolates associated with human disease [18], which may be reflective of the clonality of $\mathrm{O} 157$ isolates despite its divergence into multiple strain types [22].

3.2. PFGE Analysis of the 25 Bovine O157 Isolates. As shown in Figures 1(b), 2(b), and 3(b), PFGE analysis of the 25 bovine O157 isolates yielded complex genomic DNA electrophoresis patterns. Whether the isolates were grouped traditionally based on band differences (identical, closely related with 1-3 band differences, more distantly related with 


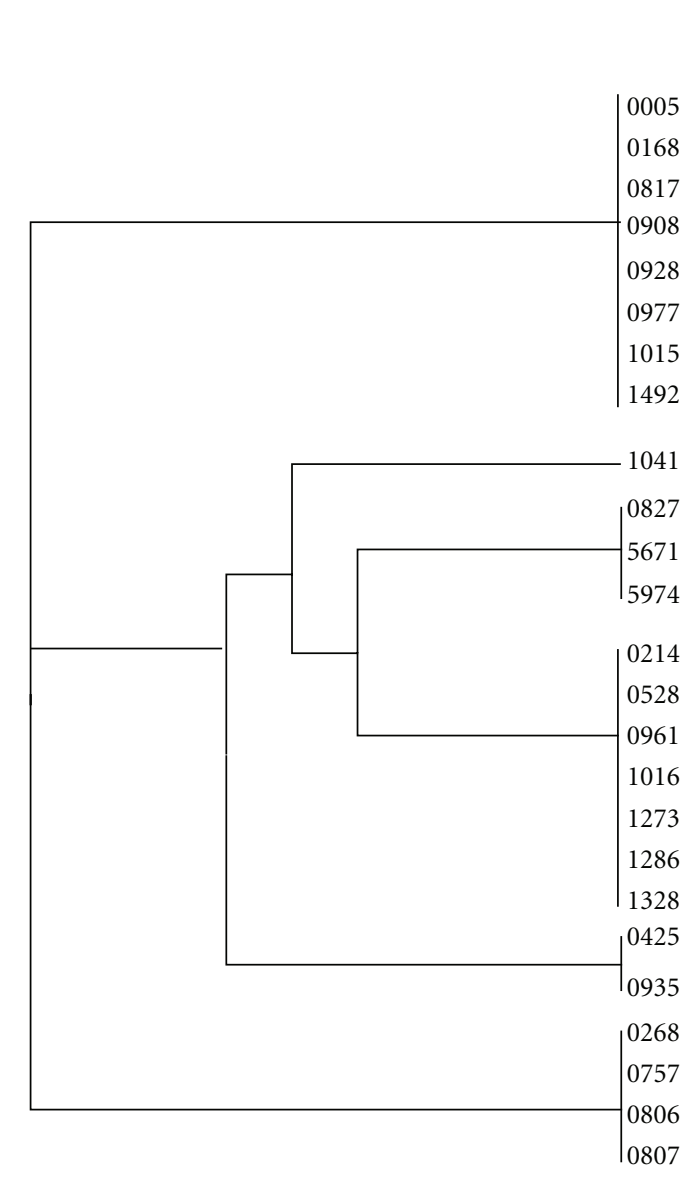

(a) AvrII-based PATS
Dice (Opt: 1\%) $(\mathrm{Tol} 2 \%-2 \%)(H>0 \% S>0 \%)$ [0\%-1.5\%] [6.6\%-90.5\%]
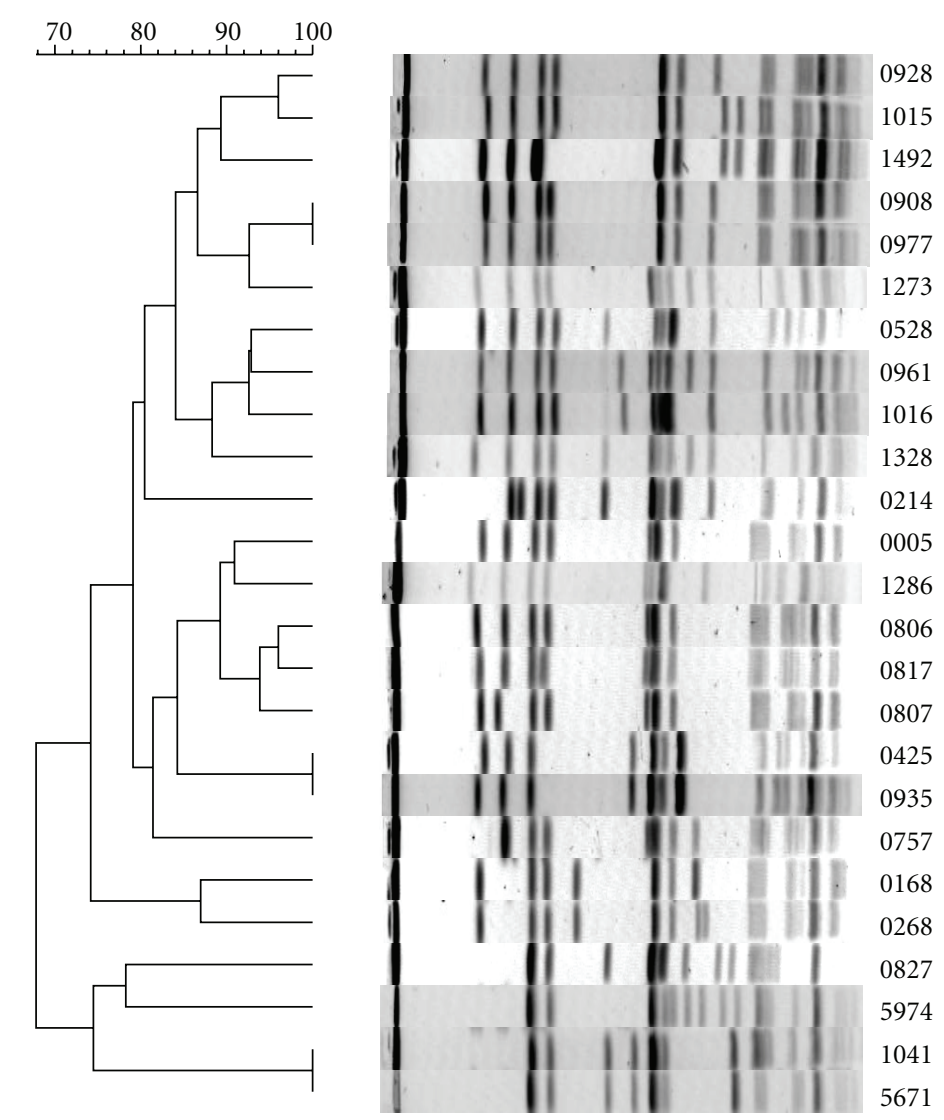

(b) AvrII-based PFGE

FIgURe 2: Analysis of relatedness between the 25 bovine O157 isolates. (a) Dendogram for AvrII-based PATS profiles was constructed using the UPGMA option in the phylogenetic analysis using parsimony (PAUP; Sinauer Associates, Inc., Publishers, Sunderland, Ma.). (b) Dendogram for AvrII-based PFGE profiles was constructed using the UPGMA cluster analysis based on Dice coefficients performed in Bionumerics (Applied Maths, Saint-Martens-Laatem, Belgium). Percent tolerance used is shown above the dendogram.

4-6 band differences) (data not shown), or grouped based on Dice similarity coefficients, the dendograms generated in Bionumerics indicated a high similarity among the isolates. Using the latter configurations, XbaI-based PFGE generated 6 clades from 23 different DNA banding patterns, AvrIIbased PFGE generated 7 clades from 22 different DNA banding patterns, and combined PFGE generated 9 clades.

\subsection{PATS Has Good Correlation with PFGE While Maintain-} ing Its Distinctive Discriminating Features. Comparison of the dendograms generated showed that about $85 \%$ of the bovine $\mathrm{O} 157$ isolates formed similar groups by PATS and PFGE, irrespective of whether it was XbaI-based ( $84 \%$ similar groups), AvrII-based ( $84 \%$ similar groups), or based on a combination of enzymes ( $88 \%$ similar groups). However, the inherent differences between the two techniques was reflected when the Dice similarity coefficients were subjected to Pearson's correlation coefficient analysis. The Pearson's correlation coefficient, $r$, was calculated at about $0.4,0.3$, and 0.4 for XbaI-based, AvrII-based and combined PATS and PFGE similarities, respectively (Figure 4). This clearly indicated that these profiles shared a good if not high correlation. This may be reflective of the two techniques assessing the same restriction site polymorphisms in a different manner; PATS directly ascertains the presence/absence/other variations at these sites, while PFGE evaluates the resulting variations in the number and sizes of the genomic DNA fragments generated post-digestion with the same restriction enzymes.

A more positive correlation was observed for the XbaIbased, and XbaI and AvrII-combined-PFGE and PATS profiles than for the AvrII-based profiles, suggesting that perhaps the latter was more discriminatory. In fact, polymorphisms at the AvrII restriction sites and the presence/absence of virulence genes increased the discriminatory ability of PATS. Although we cannot rule out the inability to resolve ambiguous patterns due to comigrating bands or incompletely digested spurious bands by PFGE, this observation with PATS lends support to some of the discrimination seen with PFGE as well $[17,18]$. Thus, the two typing techniques seem to complement each other while maintaining their own discriminative features. 


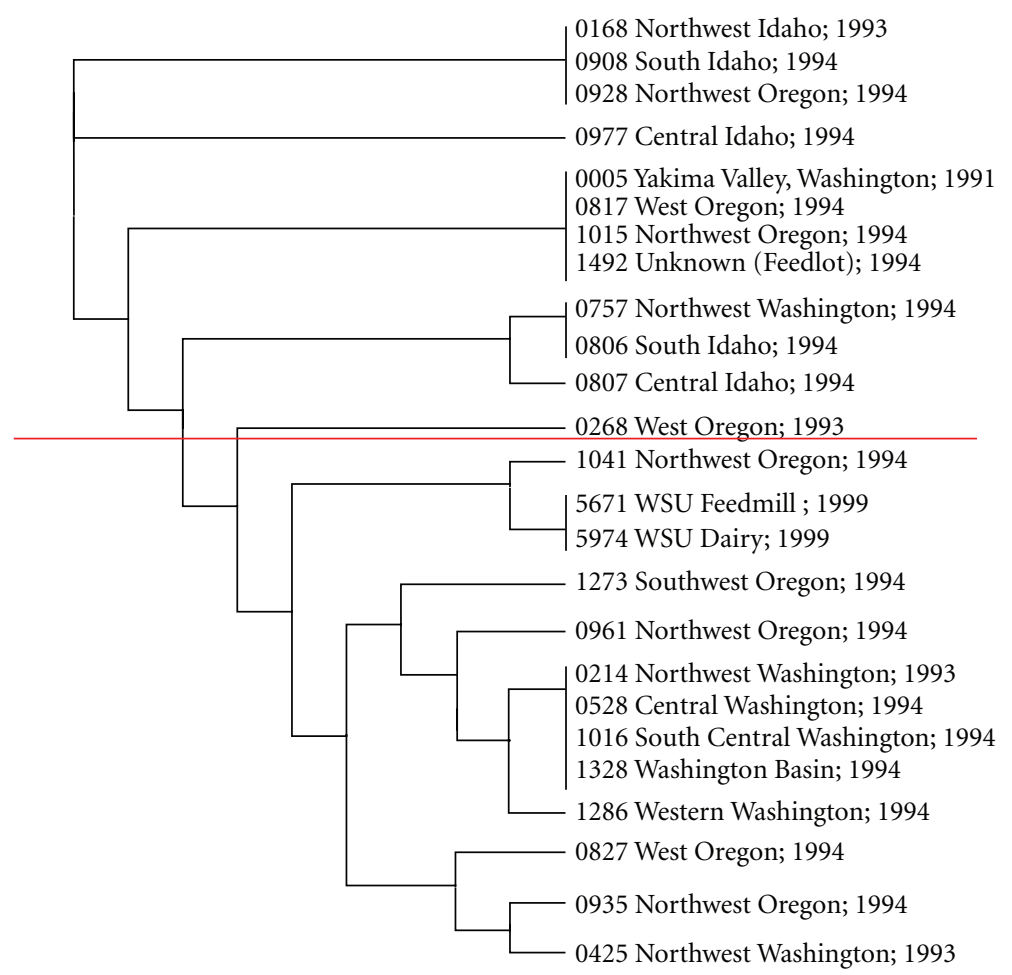

(a) Combined PATS

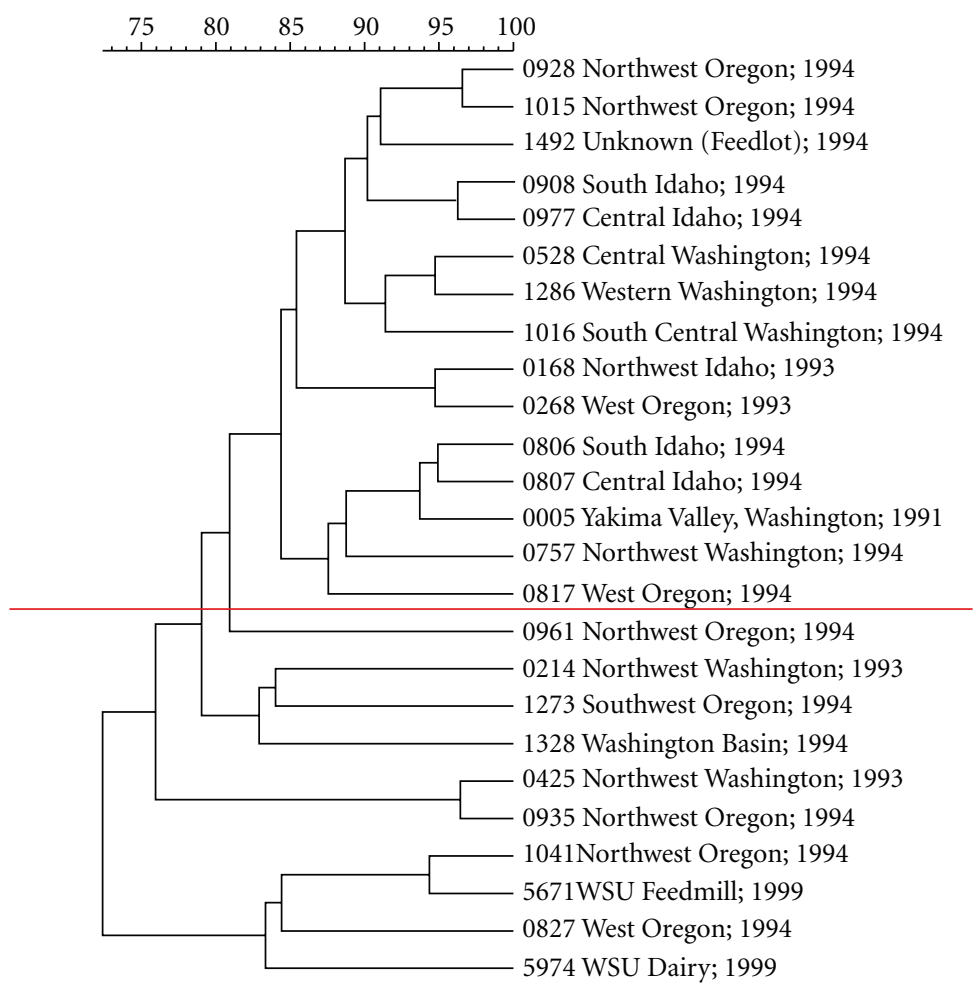

(b) Combined PFGE

FIgURe 3: Analysis of relatedness between the 25 bovine O157 isolates. (a) Dendogram for combined-PATS (XbaI-, AvrII- and virulence genes-based) profiles was constructed using the UPGMA option in the phylogenetic analysis using parsimony (PAUP; Sinauer Associates, Inc., Publishers, Sunderland, Ma.). (b) Dendogram for combined-PFGE resulting from cluster analysis of combined Dice coefficients from PFGE following digestion with XbaI and PFGE following digestion with AvrII. Red line on each dendogram delineates isolates similarly grouped by combined-PATS and combined-PFGE. 

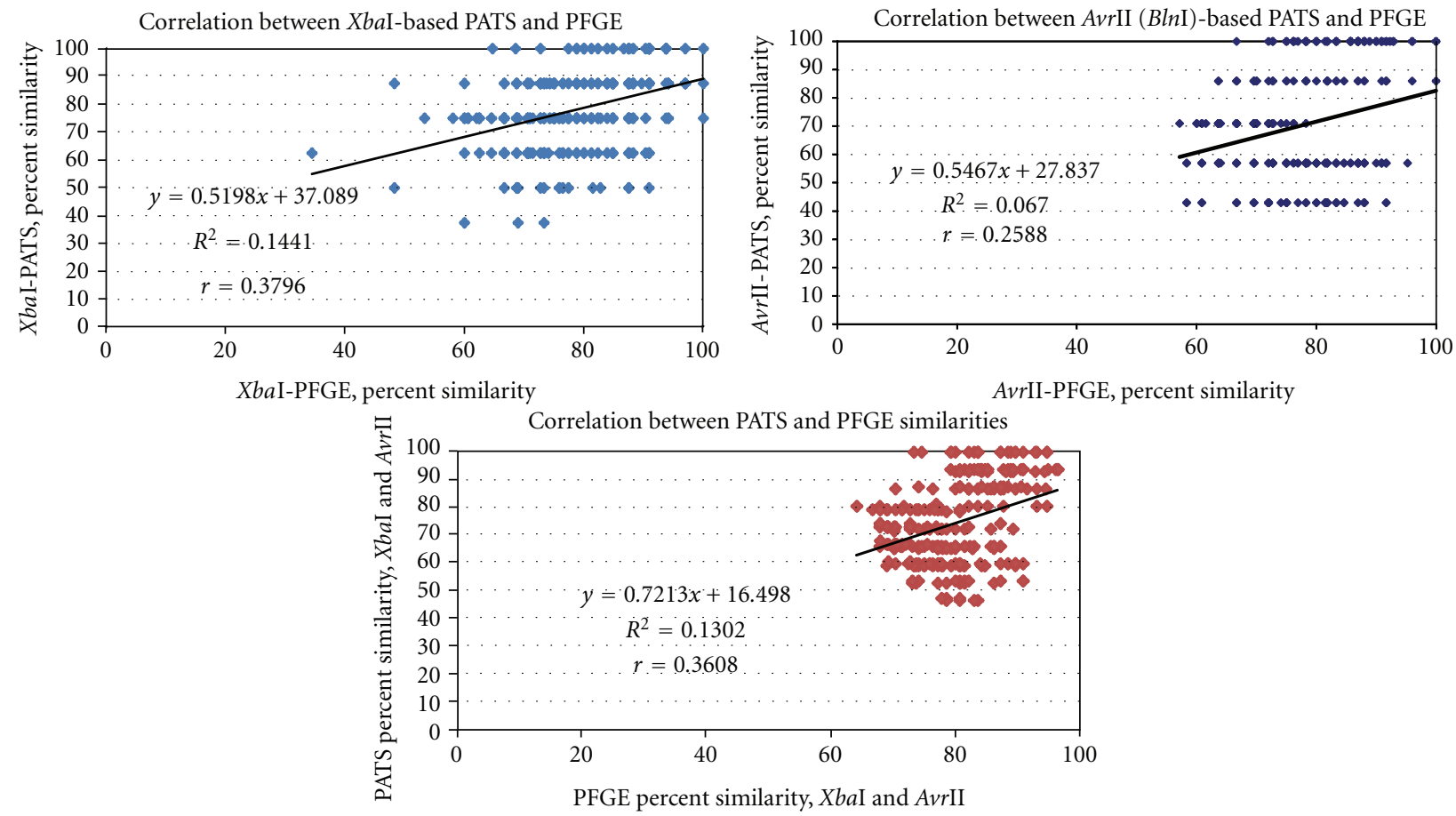

FIGURE 4: Scatter plots comparing PATS and PFGE profiles generated for 25 bovine O157 isolates. The derivation of the Pearson correlation coefficient is shown within each graph.

\section{Discussion}

The goal of this study was to compare the results of XbaI-based-, AvrII-based-, and combined-PATS with similar analyses done using PFGE, on 25 bovine O157 collected from different geographic locations to determine if these two strain typing techniques would relate and discriminate between bovine isolates in a similar manner as previously reported with human isolates. XbaI-based, AvrII-based, and combined PATS generated 5, 3, and 7 clades, respectively, reflecting the clonality of O157 (Figures 1(a) and 2(a)). A similar tendency was observed with XbaI-based (6 clades), AvrII-based (7 clades), and combined (9 clades) PFGE profiles based on the Dice coefficient similarities (Figures 1(b) and 2(b)). Clades generated with combined-PATS grouped the majority of isolates from Washington State and Idaho State in separate clusters interspersed with isolates from Oregon State (Figure 3(a)). While combined-PFGEgenerated clades did not distribute the isolates in the exact manner as combined-PATS, about $85 \%$ of the isolates maintained a similar distribution (Figure 3(b)). As this was a random study of isolates, we were unable to determine if there was any transfer of animals, feed or other farm related goods between Oregon and the other 2 states that may have caused the O157 isolates to be closely related [21]. However, in an epidemiological situation this would be a reasonable cause to verify such an exchange.

PFGE is currently the standard strain typing technique used by various epidemiological and diagnostic laboratories to estimate the relatedness of outbreak or nosocomial O157 and other bacterial isolates $[12,23]$. Compared to other strain typing methodologies being used, PFGE does provide relatively distinctive profiles for strains in several serotypes making it a popular strain typing tool. However, challenges in using PFGE are well known especially, the improper digestion and resolution of DNA bands, comigration of similar sized DNA fragments and nonhomologous DNA, or changes in electrophoretic conditions or analytical software, resulting in "untypeable" or incorrect profiles that cannot be interpreted or compared [8-11, 13, 24]. These drawbacks have led to several measures to make the PFGE protocol more uniform across laboratories, along with suggestions to use additional restriction enzymes, speed up turnaround time [13, 23, 25-29], and use other DNA sequence-based typing systems in parallel to confirm the validity of observations made with PFGE. Yet these variations continue to impede streamlining this process. Assessing genetic relatedness in a timely manner is crucial to any epidemiological survey. PFGE and DNA-sequence-based typing systems rely on expensive instrumentation and software to interpret data, which make them more useful in detailed analysis and banking of pathogens. In the field, however, a rapid and straightforward technique with sufficient power to discriminate between isolates without technical and subjective biases would help track down sources and speed up the process of sorting out linked and unlinked cases/sources in an outbreak situation. Such a technique would need to complement PFGE and not duplicate it or render the process more cumbersome.

In this study, both combined-PATS and PFGE had comparable discriminatory abilities, and the use of two restriction enzymes may have added to the observed similarities. O157 isolates that shared the same PATS group also fell into 
the same clade by PFGE. Some O157 isolates that fell into different groups/clades by the two techniques were better linked to their location using PATS which supports possible over-discrimination by PFGE. As seen previously [18], PATS was reliable, simple, user-friendly, and easy to perform and interpret in this instance as well. Because PATS is a PCRbased technique that directly addresses polymorphisms at restriction enzyme sites (Indels or SNPs), it eliminates the need for extensive electrophoresis, sequence analysis, and software to interpret results, thereby making it cost effective as well. PATS continued to maintain its high typeability and reproducibility as observed previously [18]. Based on all these observations, it appears that PATS would make an ideal "first response" epidemiological tool. We are in the process of evaluating the reliability of PATS in a "blind study" where the details of the $\mathrm{O} 157$ being typed will be withheld until the end of the study to ensure a typical field situation. We are also expanding application of PATS to other human pathogens of bovine origin such as, Shiga-toxin producing Escherichia coli (STECs), while seeking options to automate the process to further reduce the turnaround time to less than $6-8 \mathrm{hrs}$.

\section{Acknowledgments}

This study was supported in part by Grant Cooperative Agreement Number U60-CCU303019-15 from the Centers for Disease Control-Association of Public Health Laboratories to S. B. Calderwood and I. T. Kudva This work was also supported in part by the Center for Integration of Medicine and Innovative Technology (CIMIT), through U.S. Army Medical Research and Materiel Command Cooperative Agreement Number DAMD17-02-2-0006, award to S. B. Calderwood, I. T. Kudva, and M. John U.S. Utility Patent Pending for PATS-a bacterial strain typing technology (Filed Nov. 1, 2001). The work of M. A. Davis and C. J. Hovde was supported, in part, by the Idaho Agriculture Experiment Station, USDA Grant 04-04562, and Public Health Service NIH Grants P20-RR16454 (NCRR) and P20-GM103408 (NIGMS). Mention of trade names or commercial products in this paper is solely for the purpose of providing specific information and does not imply recommendation or endorsement by the U.S. Department of Agriculture. USDA is an equal opportunity provider and employer.

\section{References}

[1] P. M. Griffin, S. M. Ostroff, R. V. Tauxe et al., "Illness associated with Escherichia coli 0157:H7 infections. A broad clinical spectrum," Annals of Internal Medicine, vol. 109, no. 9, pp. 705-712, 1988.

[2] P. M. Griffin, Infections of the Gastrointestinal Tract, Raven Press, New York, NY, USA, 1995.

[3] J. B. Kaper, "The locus of enterocyte effacement pathogenicity island of Shiga toxin-producing Escherichia coli O157:H7 and other attaching and effacing E. coli," Japanese Journal of Medical Science and Biology, vol. 51, no. 1, pp. S101-S107, 1998.
[4] J. C. Paton and A. W. Paton, "Pathogenesis and diagnosis of Shiga toxin-producing Escherichia coli infections," Clinical Microbiology Reviews, vol. 11, no. 3, pp. 450-479, 1998.

[5] P. M. Griffin, P. S. Mead, T. vanGilder, S. B. Hunter, N. A. Strockbine, and R. V. Tauxe, "Shiga-toxin producing Escherichia coli infections in the United States: current status and challenges," in Proceedings of the 4th International Symposium and Workshop on Shiga Toxin (Verocytotoxin)-Producing Escherichia coli Infections (VTEC '00), 2000.

[6] E. Scallan, R. M. Hoekstra, F. J. Angulo et al., "Foodborne illness acquired in the United States-Major pathogens," Emerging Infectious Diseases, vol. 17, no. 1, pp. 7-15, 2011.

[7] D. Gilliss, A. Cronquist, M. Cartter et al., "Vital signs: incidence and trends of infection with pathogens transmitted commonly through food-foodborne diseases active surveillance network, 10 U.S. sites, 1996-2010," Morbidity and Mortality Weekly Report, vol. 60, no. 22, pp. 749-755, 2011.

[8] B. Birren and E. Lai, Pulsed-Field Gel Electrophoresis-A Practical Guide, Academic Press, San Diego, Calif, USA, 1993.

[9] K. D. Harsono, C. W. Kaspar, and J. B. Luchansky, "Comparison and genomic sizing of Escherichia coli O157:H7 isolates by pulsed-field gel electrophoresis," Applied and Environmental Microbiology, vol. 59, no. 9, pp. 3141-3144, 1993.

[10] J. M. Johnson, S. D. Weagant, K. C. Jinneman, and J. L. Bryant, "Use of pulsed-field gel electrophoresis for epidemiological study of Escherichia coli O157:H7 during a food-borne outbreak," Applied and Environmental Microbiology, vol. 61, no. 7, pp. 2806-2808, 1995.

[11] T. Murase, S. Yamai, and H. Watanabe, "Changes in pulsedfield gel electrophoresis patterns in clinical isolates of enterohemorrhagic Escherichia coli O157:H7 associated with loss of Shiga toxin genes," Current Microbiology, vol. 38, no. 1, pp. 4850, 1999.

[12] D. M. Olive and P. Bean, "Principles and applications of methods for DNA-based typing of microbial organisms," Journal of Clinical Microbiology, vol. 37, no. 6, pp. 1661-1669, 1999.

[13] M. A. Davis, D. D. Hancock, T. E. Besser, and D. R. Call, "Evaluation of pulsed-field gel electrophoresis as a tool for determining the degree of genetic relatedness between strains of Escherichia coli O157:H7," Journal of Clinical Microbiology, vol. 41, no. 5, pp. 1843-1849, 2003.

[14] A. C. Noller, M. C. McEllistrem, O. C. Stine et al., "Multilocus sequence typing reveals a lack of diversity among Escherichia coli $\mathrm{O} 157: \mathrm{H} 7$ isolates that are distinct by pulsed-field gel electrophoresis," Journal of Clinical Microbiology, vol. 41, no. 2, pp. 675-679, 2003.

[15] A. C. Noller, M. C. McEllistrem, A. G. F. Pacheco, D. J. Boxrud, and L. H. Harrison, "Multilocus variable-number tandem repeat analysis distinguishes outbreak and sporadic Escherichia coli O157:H7 isolates," Journal of Clinical Microbiology, vol. 41, no. 12, pp. 5389-5397, 2003.

[16] I. T. Kudva, P. S. Evans, N. T. Perna et al., "Strains of Escherichia coli O157:H7 differ primarily by insertions or deletions, not single-nucleotide polymorphisms," Journal of Bacteriology, vol. 184, no. 7, pp. 1873-1879, 2002.

[17] I. T. Kudva, P. S. Evans, N. T. Perna et al., "Polymorphic amplified typing sequences provide a novel approach to Escherichia coli O157:H7 strain typing," Journal of Clinical Microbiology, vol. 40, no. 4, pp. 1152-1159, 2002.

[18] I. T. Kudva, R. W. Griffin, M. Murray et al., "Insertions, deletions, and single-nucleotide polymorphisms at rare restriction enzyme sites enhance discriminatory power of polymorphic amplified typing sequences, a novel strain typing system for 
Escherichia coli O157:H7," Journal of Clinical Microbiology, vol. 42, no. 6, pp. 2388-2397, 2004.

[19] C. W. Dieffenbach and G. S. Dveksler, PCR Primer-A Laboratory Manual, Cold Spring Harbor Press, New York, NY, USA, 1995.

[20] R. H. Don, P. T. Cox, B. J. Wainwright, K. Baker, and J. S. Mattick, "'Touchdown' PCR to circumvent spurious priming during gene amplification," Nucleic Acids Research, vol. 19, no. 14, p. $4008,1991$.

[21] M. A. Davis, D. D. Hancock, T. E. Besser et al., "Correlation between geographic distance and genetic similarity in an international collection of bovine faecal Escherichia coli O157:H7 isolates," Epidemiology and Infection, vol. 131, no. 2, pp. 923930, 2003.

[22] A. N. Wetzel and J. T. LeJeune, "Clonal dissemination of Escherichia coli O157:H7 subtypes among dairy farms in Northeast Ohio," Applied and Environmental Microbiology, vol. 72, no. 4, pp. 2621-2626, 2006.

[23] E. M. Ribot, M. A. Fair, R. Gautom et al., "Standardization of pulsed-field gel electrophoresis protocols for the subtyping of Escherichia coli O157:H7, Salmonella, and Shigella for PulseNet," Foodborne Pathogens and Disease, vol. 3, no. 1, pp. 59-67, 2006.

[24] H. Bohm and H. Karch, "DNA fingerprinting of Escherichia coli O157:H7 strains by pulsed-field gel electrophoresis," Journal of Clinical Microbiology, vol. 30, no. 8, pp. 2169-2172, 1992.

[25] F. C. Tenover, R. D. Arbeit, R. V. Goering et al., "Interpreting chromosomal DNA restriction patterns produced by pulsedfield gel electrophoresis: criteria for bacterial strain typing," Journal of Clinical Microbiology, vol. 33, no. 9, pp. 2233-2239, 1995.

[26] R. K. Gautom, "Rapid pulsed-field gel electrophoresis protocol for typing of Escherichia coli O157:H7 and other gramnegative organisms in 1 day," Journal of Clinical Microbiology, vol. 35, no. 11, pp. 2977-2980, 1997.

[27] J. M. K. Koort, S. Lukinmaa, M. Rantala, E. Unkila, and A. Siitonen, "Technical improvement to prevent DNA degradation of enteric pathogens in pulsed-field gel electrophoresis," Journal of Clinical Microbiology, vol. 40, no. 9, pp. 3497-3498, 2002.

[28] S. B. Hunter, P. Vauterin, M. A. Lambert-Fair et al., "Establishment of a universal size standard strain for use with the pulsenet standardized pulsed-field gel electrophoresis protocols: converting the national databases to the new size standard," Journal of Clinical Microbiology, vol. 43, no. 3, pp. 1045-1050, 2005.

[29] A. Rementeria, L. Gallego, G. Quindós, and J. Garaizar, "Comparative evaluation of three commercial software packages for analysis of DNA polymorphism patterns," Clinical Microbiology and Infection, vol. 7, no. 6, pp. 331-336, 2001. 

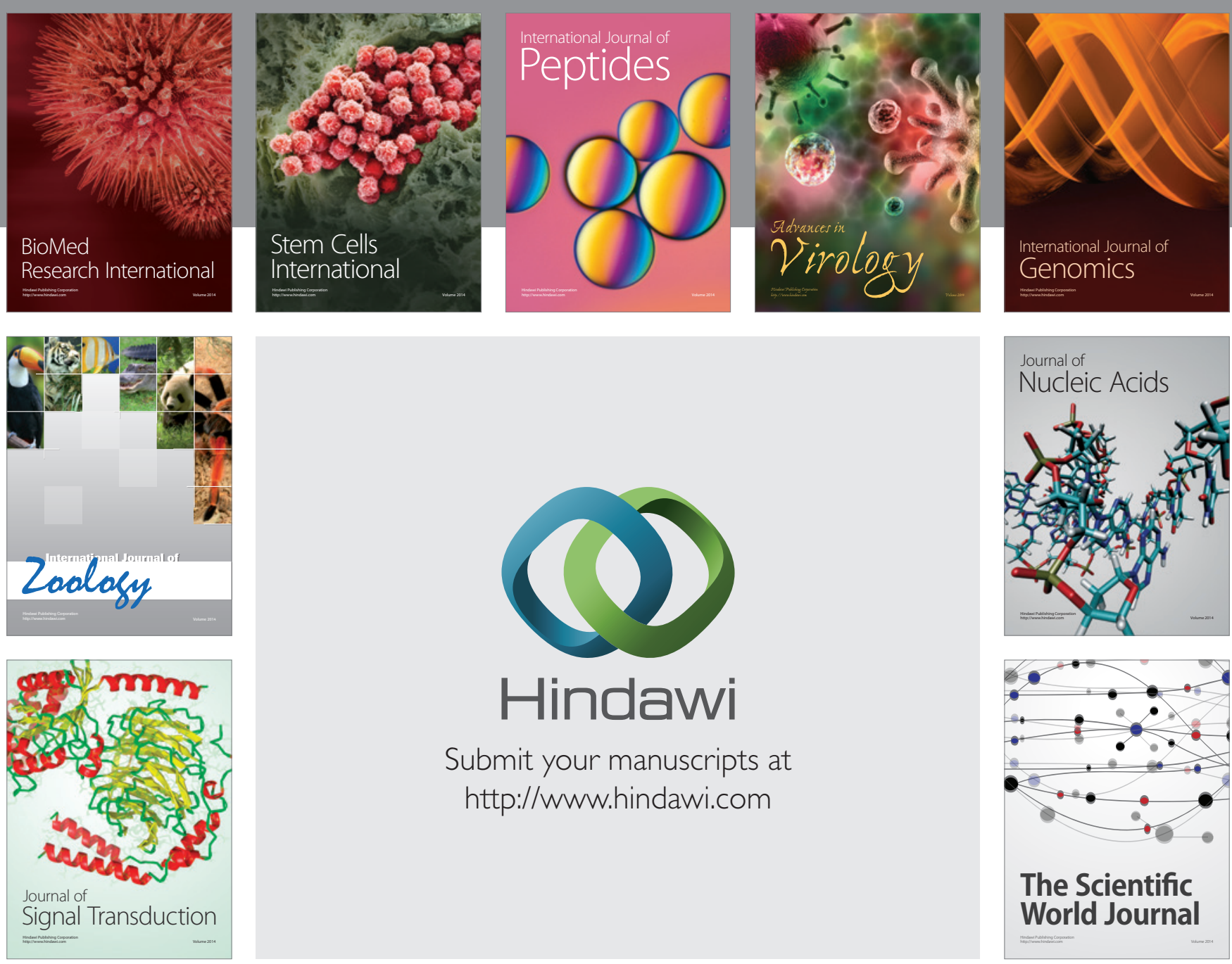

Submit your manuscripts at

http://www.hindawi.com
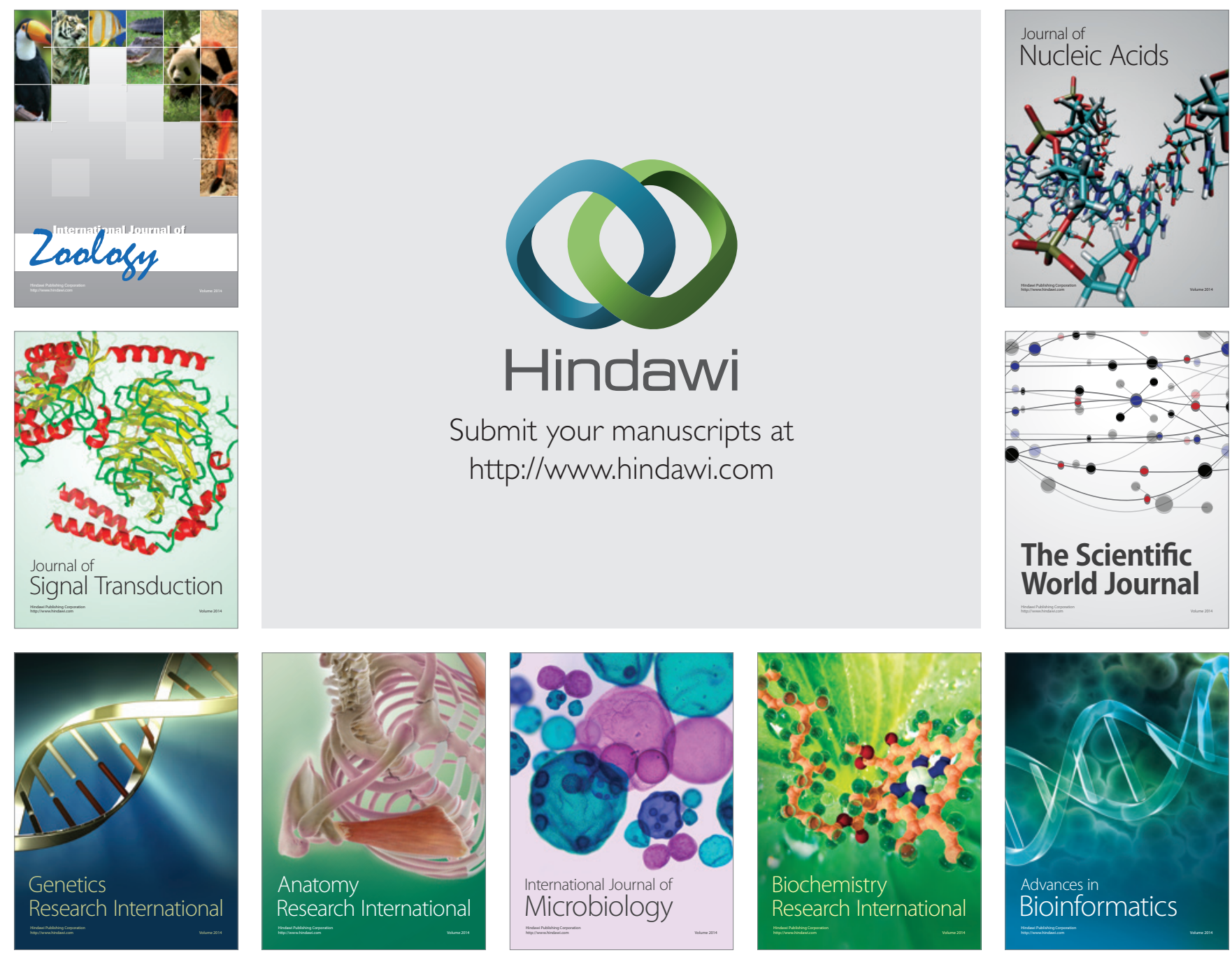

The Scientific World Journal
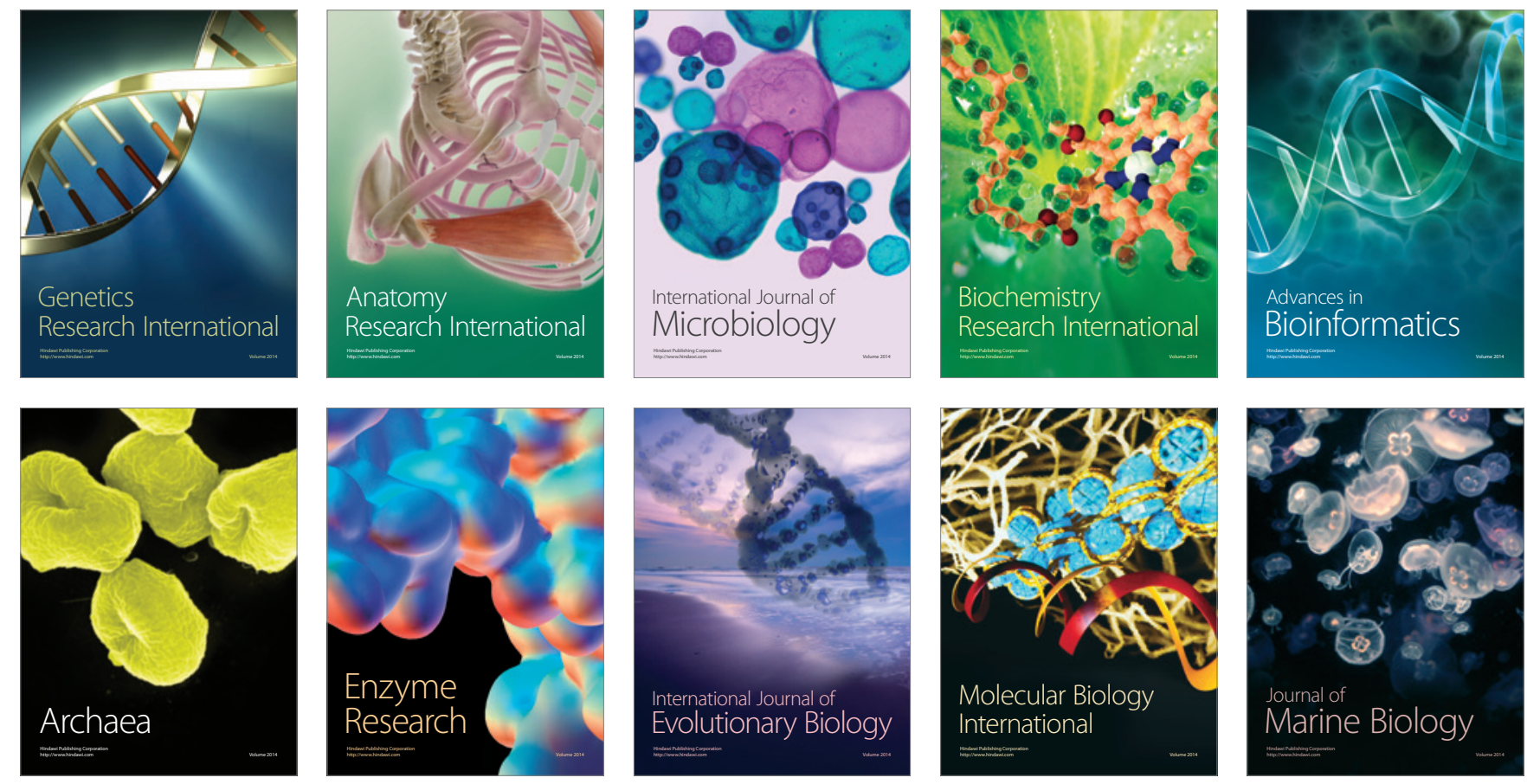